\title{
Study on the Application of BIM and VE in Construction Scheme Optimization
}

\author{
Dongsheng $\mathrm{Yu}^{1, \mathrm{a}}$ and Jintuan Zhang ${ }^{1, \mathrm{~b}^{*}}$ \\ ${ }^{1}$ Hezhou University in Guangxi, China \\ ayudongshengbmd@163.com, b349853900@qq.com \\ *The corresponding author
}

Keywords: BIM; VE; Construction Scheme; Optimization

\begin{abstract}
Construction scheme is established according to the construction project, it's a technical document which has an important influence on the quality and safety of engineering construction. The paper researches how to obtain a better construction scheme by using BIM and VE. In order to provide a solution that selects a better construction scheme form lots of construction schemes in civil engineering.
\end{abstract}

\section{Introduction}

Civil engineering construction scheme is a technical document which usually used to guide the construction, and the construction scheme has great influence on the quality, safety and cost of the engineering project. In order to optimize and evaluate the construction scheme, some scholars have done a lot of research. Xiaodong Song ${ }^{[1]}$ used value engineering to optimize the construction scheme of pile foundation. Yankui Wang ${ }^{[2]}$ had optimized dynamic layout scheme of construction site by using BIM. Liping $\mathrm{Wu}{ }^{[3]}$ used AHP to establish the evaluation model, qualitative and quantitative methods are employed to choose construction site layout scheme. The paper on the basis of previous studies put BIM and VE into optimizing construction scheme, and sum up the application of BIM technology and value engineering method for the selection of construction plan, in order to provide an effective way for the selection of construction plans.

\section{BIM Survey}

BIM(Building Information Modeling)is a kind of multidimensional model information integration technology which developed based on CAD technology. The participants of the project construction can operate the information in the digital virtual building model and operate the model in the information. BIM could improve the efficiency and quality of the whole life cycle of the building so as to reduce the risk of errors and risks, BIM has the characteristics of visualization, coordination, simulation, optimization, and drawing. BIM can be applied to decision-making, design, construction, operation and maintenance of the whole project process ${ }^{[4]}$.

Based on the advantage of BIM, we can use BIM as carrier to make the construction scheme visualization and simulation when prepare the scheme. And we can demonstrate the technical indicators and functions of the construction schemes in three dimensions, at the same time reduce the cost by using BIM.

Every components' information (such as size, quantity, etc.) can be extracted from the construction plans' model which established by using BIM, and the cost of construction plan can be obtained easily. However, BIM can only describe some of the technical features of the construction programs, couldn't quantify every functions of the program. Even though the cost of the construction program can be determined directly by using BIM, but the function of each programs can not be quantified, the appropriate construction plan couldn't be selected. At this time we need to employ VE. 


\section{VE Summary}

Value Engineering (VE) is the thinking method and management technology that could achieve the necessary functions of the research object reliably and improve the value of object in the lowest life cycle cost. The "value" of VE is the ratio between the function of the analysis object and the cost of obtaining the function and using the function ${ }^{[5]}$.

To quantify the function of the construction plan, The functional coefficient of the plan can be determined by the "01" scoring method, direct scoring method, "04" scoring method, etc. And the method for determining the cost coefficient is that the cost of each construction scheme is divided by the sum of the cost of each construction plan.

\section{Analysis about the Path Selects the Construction Plan by Using BIM and VE}

The various functions of each construction plans can be shown visually and completely by using BIM, so that the functional coefficient of each plans could be determined directly. Through the construction of the BIM model, we can get the cost of the construction program, Then determine the value of the various construction projects, and ultimately determine the optimal construction plan. It can be said that the BIM technology and the VE are two ways to renew and supplement each other.

Determine the Selection Object. In the engineering construction, there may be different construction schemes in the same construction process, and each construction schemes play the technical and economic effect is different. So in actual engineering we need to prepare a number of construction plans as the evaluation object based on the advantages of BIM technology, In order to achieve the appreciation of the value of construction schemes and access the highest cost of construction plans.

Functional Analysis of Construction Scheme. According to the practical experience of the past, the required construction plan should consider the construction safety, construction quality, construction period, cost and technical feasibility. On the basis of the above requirements of the basic construction plan, the construction scheme based on the BIM technology should also consider the simulation effect of the construction scheme, and the factors that must be considered for later optimization. When determining the functional coefficient of the construction scheme, the scoring method can be used to evaluate the technical indexes of the construction scheme.

Cost Analysis of Construction Scheme. In the construction plan of the BIM model, we can extract the engineering quantity and consumption of artificial, mechanical and other indicators in the construction plan, and multiplied by the corresponding comprehensive unit price to determine the cost of each construction plans. According to the method of cost coefficient determination, the cost coefficient of each construction scheme can be determined.

Construction Scheme Selection. Select the construction scheme that the value coefficient is largest as optimization scheme based on $\mathrm{V}=\mathrm{F} / \mathrm{C}$. Because of BIM owns the characteristics of optimization, we can further optimize the construction scheme which be selected finally based on $\mathrm{V}=\mathrm{F} / \mathrm{C}$. At this point, we only need to modify the BIM model of the construction plan, when the BIM model get modified, the other information of the model could be modified. Improve the fidelity of the convenience and the fidelity of information greatly.

\section{Conclusion}

Taking into account the importance of the construction plan, BIM technology and value engineering were applied to the selection of construction scheme in this paper. The paper revealed the characteristics of mutual continuity and complementary between BIM and VE, summarized the application steps of both using BIM and VE, hoping to provide a solution for the optimization of the construction scheme in civil engineering construction. 


\section{Acknowledgements}

1.ScienceResearchand Technology Development Project of Guangxi(15122001-3-18)

2.Young teachers' basic capacity improvement program of Guangxi (KY2016LX379)

3.Research Project of Hezhou University(2014ZD03)

\section{References}

[1] X.D. Song: Journal of Changsha University, Vol. 23 (2009) No.5,pp.52-54.(In Chinese)

[2] K.Y. Wang, J. Zheng: Construction Technology, Vol. 43 (2014) No.3,pp.72-76.(In Chinese)

[3] L.P. Wu, Y. Feng and G. LI: Journal of Zhejiang University of Technology, (2014) No.001,pp.111-113.(In Chinese)

[4] W.L. Ge, X.M. Yu and B. He: BIM Second Dimension--BIM Application of Different Project Participants (China Architecture \& Building Press, China 2011).

[5] X.J. Liu: Engineering Economics (Second Edition) (China Architecture \& Building Press, China 2011). 